\title{
Gait Rehabilitation for Foot and Ankle Impairments in Early Rheumatoid Arthritis: a Feasibility Study of a New Gait Rehabilitation Programme (GREAT Strides)
}

Gordon Hendry ( $\nabla$ gordon.hendry@gcu.ac.uk)

Glasgow Caledonian University School of Health and Life Sciences https://orcid.org/0000-0003-16117193

\section{Lindsay Bearne}

St George's University of London

\section{Nadine E Foster}

The University of Queensland

Emma L Godfrey

King's College London

\section{Samantha Hider}

Keele University

Lisa Jolly

NHS Greater Glasgow and Clyde

Helen Mason

Glasgow Caledonian University

Alex McConnachie

University of Glasgow

lain B Mclnnes

University of Glasgow

\section{Aimie Patience}

Glasgow Caledonian University

\section{Catherine Sackley}

University of Nottingham

\section{Mandeep Sekhon}

King's College London

\section{Bethany Stanley}

University of Glasgow

\section{Marike Van Der Leeden}

Amsterdam UMC: Amsterdam Universitair Medische Centra

Anita Williams

University of Salford 


\section{Jim Woodburn}

Griffith University

Martijn Steultjens

Glasgow Caledonian University

\section{Research Article}

Keywords: gait rehabilitation, rheumatoid arthritis, feasibility

Posted Date: January 11th, 2022

DOI: https://doi.org/10.21203/rs.3.rs-1124021/v1

License: (c) (i) This work is licensed under a Creative Commons Attribution 4.0 International License. Read Full License 


\section{Abstract}

\section{Background}

Foot impairments in early rheumatoid arthritis are common and lead to progressive deterioration of lower limb function. A gait rehabilitation programme underpinned by psychological techniques to improve adherence, may preserve gait and lower limb function. This study evaluated the feasibility of a novel gait rehabilitation intervention (GREAT Strides) and a future trial.

\section{Methods}

This was a mixed methods feasibility study with embedded qualitative components. People with early ( $<2$ years) rheumatoid arthritis (RA) and foot pain were eligible. Intervention acceptability was evaluated using a questionnaire. Adherence was evaluated using the Exercise Adherence Rating Scale (EARS). Safety was monitored using case report forms. Participants and therapists were interviewed to explore intervention acceptability. Deductive thematic analysis was applied using the Theoretical Framework of Acceptability. For fidelity, audio recordings of interventions sessions were assessed using the Motivational Interviewing Treatment Integrity (MITI) scale. Measurement properties of four candidate primary outcomes, rates of recruitment, attrition and data completeness were evaluated.

\section{Results}

35 participants (68.6\% female) with median age (inter-quartile range [IQR]) 60.1 [49.4-68.4] years and disease duration 9.1 [4.0-16.2] months), were recruited and 23 (65.7\%) completed 12-week follow-up. Intervention acceptability was excellent; $21 / 23$ were confident that it could help and would recommend it; $22 / 23$ indicated it made sense to them. Adherence was good, with a median [IQR] EARS score of 17/24 [12.5-22.5]. One serious adverse event that was unrelated to the study was reported. Twelve participants' and 9 therapists' interviews confirmed intervention acceptability, identified perceptions of benefit, but also highlighted some barriers to completion. Mean MITI scores for relational (4.38) and technical (4.19) aspects of motivational interviewing demonstrate good fidelity. The Foot Function Index disability subscale performed best in terms of theoretical consistency and was deemed most practical.

\section{Conclusion}

GREAT Strides was viewed as acceptable by patients and therapists, and we observed high intervention fidelity, good patient adherence and no safety concerns. A future trial to test the additional benefit of GREAT Strides to usual care will benefit from amended eligibility criteria, refinement of the intervention and strategies to ensure higher follow-up rates. The Foot Function Index disability subscale was identified as the primary outcome.

\section{Trial registration}

ISRCTN14277030 


\section{Key Messages Regarding Feasibility}

\section{1) What uncertainties existed regarding the feasibility?}

Prior to evaluation via a future randomised controlled trial, we wanted to establish whether the newly developed GREAT Strides gait rehabilitation programme was likely to be safe and acceptable to people with early RA. We also sought to establish whether GREAT Strides would be acceptable to therapists (podiatrists and physiotherapists) responsible for its delivery, and whether it could be delivered as intended. Prior to evaluation in a randomised trial, uncertainty about the best and most practical outcome measure in terms of ability to detect change for use as primary outcome measure. Uncertainty also existed concerning the feasibility of a main trial in terms of recruitment and retention rates relative to sample size requirements.

\section{2) What are the key feasibility findings?}

We identified that GREAT Strides was likely to be safe, had excellent patient acceptability, and resulted in good patient adherence. GREAT Strides was acceptable to intervention therapists and was delivered with high fidelity. Recommendations are provided for primary outcome measure selection for a future main trial (the Foot Function Index Disability subscale). Recruitment and retention rates were lower than anticipated and require further strategies in a future main trial.

\section{3) What are the implications of the feasibility findings for the design of the main study?}

Results from evaluation of patient acceptability and adherence are promising and warrant further evaluation of the added benefit of GREAT Strides to usual care in a randomised trial. Evaluations of patient and therapist acceptability and fidelity have informed important refinements of the GREAT Strides intervention and therapists' intervention training format and resources. The Foot Function Index disability subscale is recommended as the primary outcome for the future randomised trial on the basis of it appearing to be the most theoretically consistent and its practical characteristics. Recruitment and retention rates observed necessitated refinement of eligibility criteria, follow-up procedures, and data collection methods and will be tested in a pilot randomised trial.

\section{Background}

Approximately 645,000 people have rheumatoid arthritis (RA) in the UK and most will experience foot and mobility problems [1-3]. In early disease around $60-65 \%$ of patients experience foot pain and joint swelling, and walking-related disability which may be persistent and progressive [4]. People with RA often exhibit slow and unsteady gait characterised by decreased walking speed, ankle power, and step length [5-7]. They take fewer steps and are more sedentary than healthy adults [8-11]. These sedentary characteristics are associated with poor body composition and elevated cardiovascular disease risk [1214]. Deteriorations in gait characterised by lower limb muscle weakness, poor muscle endurance, and reduced proprioception/balance are common and are associated with impaired physical function and 
difficulties with activities of daily living $[6,7,15-22]$. There may be a therapeutic 'window of opportunity' for preservation of gait and prevention of persistent walking disability during early disease.

Exercise is a key treatment for people with RA but adherence to exercise tends to be poor. This may be due to concerns about safety, lack of knowledge or skills or individuals' beliefs about exercise. These concerns may be exacerbated in people with depression/anxiety or poor exercise self-efficacy [23, 2729]. To address these concerns accurate information about exercise and strategies to enhance motivation and exercise self-efficacy are needed. Targeting these factors in a theoretically-informed behaviour change intervention is recommended [30], as there is strong evidence that weight-bearing exercises and physical activity are safe and do not cause disease exacerbations or joint damage [10].

Gait rehabilitation that includes repetitive practice of gait cycles is an evidence based treatment to improve independent walking capacity in neurological disorders [31-36]. Two studies have demonstrated benefits in walking capacity in people with RA from rehabilitation programmes which included repetitive walking tasks $[37,38]$. Whilst walking is generally promoted as a healthy behaviour, gait rehabilitation is not included in clinical guidelines nor provided as part of usual care for people with early RA. We developed and investigated the feasibility and acceptability of a novel psychologically informed gait rehabilitation intervention for adults with early RA (GREAT Strides) and investigated key parameters for assessment in a future randomised controlled trial.

\section{Methods/design}

\section{Aims and objectives}

The study objectives were to (i) evaluate feasibility and acceptability of GREAT- strides; and (ii) the feasibility of a future trial. More specifically, aims were:

1. To evaluate patient and therapists' perceptions of acceptability of the gait rehabilitation intervention.

2. To evaluate the initial safety of, and adherence to the gait rehabilitation intervention.

3. To evaluate the fidelity of intervention therapist training and delivery of the gait rehabilitation intervention.

4. To evaluate selected measurement properties and characteristics of candidate outcome measures to select the most suitable primary outcome measure for a future main trial.

5. To monitor rates of recruitment, attrition and data completeness.

\section{Design}

This study was a multi-centre $(n=4)$, a single-arm, repeated measures (pre- and post-intervention) design with nested qualitative studies. This feasibility study was reviewed and approved by the West of Scotland Research Ethics Committee 3 (17/WS/0264) in January 2017.

\section{Settings}


The study was conducted in outpatient rheumatology (recruitment) and rehabilitation (physiotherapy and podiatry) settings in 4 United Kingdom National Health Service (NHS) Hospitals in Glasgow (Gartnavel General Hospital and Glasgow Royal Infirmary, NHS Greater Glasgow and Clyde), Stoke-on-Trent (Haywood Hospital, Midlands Partnership Foundation Trust), and London (King's College Hospital NHS Foundations Trust).

\section{Participants}

Participants were included if they: (a) were aged $\geq 18$ years, (b) diagnosed with RA (American College of Rheumatology (ACR) 2010 classification criteria [41]) within the previous 2 years, (c) had disease-related foot impairments defined as: (i) self-reported foot pain, and/or (ii) the presence of foot/ankle joint synovitis/tenosynovitis detected during routine rheumatology clinical examination. Exclusion criteria included contraindications to the intervention identified by their consulting rheumatologist, those who were unable or unwilling to provide informed consent; or were taking part in other non-medical intervention studies affecting lower limb function.

\section{Recruitment}

Potential participants were identified by rheumatology team members in one of two ways. Rheumatology clinic lists were screened by the direct care team and potentially eligible patients who were interested in the study were introduced to the research team. A second approach involved initial screening of clinic lists by trial personnel at participating sites. Written invitation letters were sent to potentially eligible patients. Patients interested in the study responded using an expression of interest form, and were contacted by the recruiting researcher to confirm eligibility and willingness to participate. Once eligibility was confirmed, all eligible patients were invited to attend an initial appointment where written informed consent was obtained and baseline assessment completed.

\section{Intervention development}

Informed by MRC guidelines for the development of complex interventions [39], GREAT Strides was developed by people with RA, rheumatology specialist physiotherapists, podiatrists, health psychologists and clinical academics experienced in intervention development. It drew on existing exercise programmes for older adults and people with RA [37, 38, 42-45], and incorporated psychological components to address adherence [46-49]. a series of Patient and Public Involvement (PPI) and stakeholder engagement workshops/interviews were conducted. At the final workshop, the specific intervention components and therapist training plans were agreed by consensus.

\section{The GREAT Strides intervention}

GREAT Strides is a theoretically underpinned psychologically informed home-based 12-week gait rehabilitation programme which included two compulsory face-to-face sessions and up to four additional sessions with trained therapists over a 12-week period. GREAT Strides was comprised of

a. A circuit of six repetitive walking tasks designed for setup and completion at home (Figure 1). 
b. The psychological components of GREAT Strides are based upon motivational interviewing (MI) to support participants to overcome barriers and facilitate translation of intentions into action [46, 47]. $\mathrm{MI}$ is a collaborative, goal-oriented style of communication where particular attention is paid to the language of change [47]. GREAT Strides is underpinned by the Theory of Planned Behaviour (TBP) $[48,49]$. This model places emphasis on individuals' perceived ability to perform a given behaviour and their attitudes to initiating behavioural change [50]. Specific behaviour change techniques (BCTs) have been incorporated into the intervention to facilitate adherence (Table 1).

c. Participants were provided with an educational booklet, an exercise diary, and a digital versatile disc (DVD) including step-by-step demonstrations of gait circuit home set-up and task completion. All resources were also available on a dedicated study website [53].

Session 1 involves six core components: an overview of the intervention, brief clinical assessment of disease activity and functional status, conducing a psychological assessment using the principles of motivational interviewing. demonstration of the circuit, dose setting, and the delivery of 17 BCTs (Table 1), and provision of support materials. Session 2 (1-4 weeks after session 1) involved delivery of 4 core components and 12 BCTs (Table 1), further dose and circuit adaptation as required. Sessions 3-6 were optional (same core components and BCTs as session 2) and could be face-to-face or telephone-based according to participants' needs to maintain contact, promote adherence and/or to provide specific advice regarding progression.

The setting of the starting dose is undertaken by instructing participants to complete one full set of the circuit (1 minute per task) followed by immediate rating of perceived exertion using a modified version of the Borg Rating of Perceived Exertion (RPE) scale (range 6-20). The starting dose equals the number of sets required to achieve an RPE from 13 up to 17 (equivalent to 50-80\% maximal exertion) [51, 52] and frequency set initially at 3 times per week. 
Table 1

The core components and BCTs for GREAT Strides intervention sessions.

\section{Session 1}

Core components

Gives a short overview of the GREAT intervention.

Conducts a brief clinical assessment.

Conducts a psychological assessment using the principles of motivational interviewing.

Completes the worksheets from the patient support booklet.

Gives patient a DVD and manual.

Confirms appointment for session 2.

Sessions 2-4

Verbal persuasion about capability.

Discuss

discrepancy between current behaviour and goals.

Discuss pros and cons.

Demonstration of the behaviour.

Instructions on how to perform the behaviour.

Behaviour practice/rehearsal.

Feedback on behaviour.

Goal setting

(behaviour).

Goal setting

(outcome).

Problem solving.

Action planning.

Graded tasks.

Prompts and cues.

Self-monitoring of behaviour.

Social support.

Commitment.
Core components

Review progress on gait circuit.

Checks gait circuit progression.

\section{BCTs}

Verbal persuasion about capability.

Review behavioural goal.

Completes and/or reviews the worksheets from the patient support booklet.

Feedback on behaviour.

Problem solving.

Signposts to local walking groups.

Goal setting (outcome).

Social support (unspecified).

Demonstration of the behaviour.

Instructions on how to perform the behaviour.

Behaviour practice/rehearsal.

Goal setting (behaviour).

Graded tasks.

Action planning. 


\section{Therapist intervention training}

Eleven therapists across the three sites received a bespoke training package (8 hours training over two days delivered face to face two weeks apart) to deliver GREAT Strides. Training was delivered by the GREAT trial team (GJH, AP, LB, EG, MS). It included set up and delivery of the gait circuit, dose setting, and how to apply $\mathrm{MI}$ and BCTs to help patients complete their walking exercises regularly. Therapists were also provided with a clinician manual to accompany the training content and access to electronic resources on the study website [53].

\section{Feasibility outcomes}

\section{Intervention acceptability, safety and adherence}

Participant acceptability was evaluated using a 3-item questionnaire which utilises 5-point Likert scales for responses, adapted from previous trials $[54,55]$. Study and intervention safety were monitored by examining rates of serious adverse events (SAEs) and expected events of interest (see Additional File 1) deemed to be related to the intervention. Treatment adherence was evaluated using the Exercise Adherence Rating Scale (EARS), a valid and reliable self-reported measure of adherence to prescribed exercise therapies [56].

\section{Qualitative explorations of intervention acceptability, adherence and safety}

\section{Patient interviews}

A purposive sub-sample of participants were identified at the end of the 12-week intervention period for telephone interviews by an independent researcher (AW). The interview was conversational in style and allowed the participant to speak freely about their experience and opinions. Several trigger questions were used to keep the conversation focussed (Additional File 2). The interview was recorded using a digital recorder and data transcribed verbatim by a commercial company (Outsec Services Limited, Swaffham, UK). Thematic analysis was undertaken initially using a thematic network approach [57]. Thematic analyses were independently verified by an additional qualitative researcher. At the third iteration of interpretation, relevant themes were aligned to the Theoretical Framework of Acceptability (TFA) for healthcare interventions [58].

\section{Therapist interviews}

All therapists were invited to attend a telephone semi-structured interview to explore the acceptability of training and delivery of GREAT Strides. A topic guide informed by the TFA was developed a priori [58] (Additional File 3). One researcher (MS) conducted all interviews, and data were transcribed verbatim by a commercial company (The Typing Works, Middlesex, UK). A deductive thematic analysis was applied in which the TFA was applied as the coding framework. Data were coded into six TFA constructs (affective attitude; burden; intervention coherence; opportunity costs; perceived effectiveness; self-efficacy). 
Inductive themes within each of the TFA constructs were reviewed amongst the primary coder (MS) and two additional qualitative researchers (LB, EG), until consensus was reached.

\section{Fidelity of motivational interviewing delivery}

All GREAT Strides sessions were audio recorded. Randomly selected 20-minute segments of audio recordings were rated for proficiency of MI delivery by two trained, independent raters using the Motivational Interviewing Treatment Integrity Scale 4.2.1 (MITI, 4.2.1) [59]. Motivational Interviewing technical proficiency (application of MI techniques [range 1-5] 3=fair proficiency) and relational proficiency (interpersonal style [range 1-5] 3.5=fair proficiency) were assessed.

\section{Behaviour Change Techniques delivery}

Bespoke checklists were developed to assess fidelity of delivery of 6 core intervention components delivered in sessions 1, 4 core components delivered in sessions 2-6, 17 BCTs delivered in session 1, and 12 BCTs delivered in sessions 2-6. Two independent assessors trained in applying the Behaviour Change Technique Taxonomy V1 [60] rated the full audio recordings of GREAT sessions. High treatment fidelity was calculated according to whether a minimum of $80 \%$ of core components and BCTs within each session were rated as being fully delivered by clinicians.

\section{Candidate primary outcome measures for the future trial}

Four measures of lower limb/foot disability with good measurement properties in people with RA [61-65] were selected for evaluation as potentially suitable primary outcome measures for the future randomised controlled trial. The Foot Function Index (FFI) disability subscale is a patient-reported outcome measure designed to measure self-reported foot-related disability. Responses are made using $100 \mathrm{~mm}$ visual analogue scales and a summary score obtained by calculating the mean of the nine items, with higher scores indicative of greater foot-related disability [61]. The Patient Reported Outcome Measurement Information System Physical Function Short Form (PROMIS PF-20) is an outcome measure of physical function [62]. Responses are made using twenty 5-level Likert scales, and summary score calculated by summating and converting to a T-score ranging from 9.2-62.7, with lower scores indicative of greater functional impairment. The Recent-Onset Arthritis Disability (ROADles) lower extremity subscale is a measure of lower extremity physical function [63]. Responses are made using four 5-point Likert scales and scores summated and normalised (scores $x$ 0.625) to a summary score ranging from 0-10 (higher scores representing poorer status). The 10-metre walk test (10MWT) is an objective measure of walking capacity/functional mobility. It is the time taken to walk 10 metres with greater time indicative of poorer functional status. Participants' perceptions of the overall treatment effect were recorded at 12-week follow-up using a 7-point global rating of change scale (defined as change in walking ability [CWA]) as a patient-rated anchor [66] from "Very much worse" to "Very much better".

\section{Recruitment rates, attrition, and data completeness}

Future trial feasibility was further explored through examination of recruitment rates, rates of attrition, and rates of completion of outcome measures. 


\section{Study schedule and procedures}

Study schedule and procedures details are provided in Table 2.

Table 2

Standard Protocol Items: Recommendations for Interventional Trials (SPIRIT) table for study procedures.

\begin{tabular}{|c|c|c|c|c|c|c|}
\hline & $\begin{array}{l}\text { Pre study } \\
\text { screening/ } \\
\text { consent } \\
-1\end{array}$ & $\begin{array}{l}\text { Baseline } \\
0\end{array}$ & $\begin{array}{l}\text { Compulsory } \\
\text { clinical visit } \\
1 \\
\text { T1 }\end{array}$ & $\begin{array}{l}\text { Compulsory } \\
\text { clinical visit } \\
2 \\
\text { T2 }\end{array}$ & $\begin{array}{l}\text { Optional } \\
\text { clinical } \\
\text { visits 3-6 } \\
\text { T3-6 }\end{array}$ & $\begin{array}{l}12 \\
\text { weeks } \\
\text { follow } \\
\text { up } \\
\text { F1 }\end{array}$ \\
\hline \multicolumn{7}{|l|}{ Enrolment } \\
\hline Eligibility screen & $x$ & & & & & \\
\hline $\begin{array}{l}\text { Informed } \\
\text { consent }\end{array}$ & $x$ & & & & & \\
\hline \multicolumn{7}{|l|}{ Measurements } \\
\hline $\begin{array}{l}\text { Patient } \\
\text { acceptability } \\
\text { questionnaire }\end{array}$ & & & & & & $x$ \\
\hline EARS & & & & & & $x$ \\
\hline FFI-DS & & $\mathrm{x}$ & & & & $x$ \\
\hline PROMIS PF-20 & & $x$ & & & & $x$ \\
\hline ROADles & & $x$ & & & & $x$ \\
\hline 10MWT & & $x$ & & & & $x$ \\
\hline $\begin{array}{l}\text { CWA } 7 \text { point } \\
\text { scale }\end{array}$ & & & & & & $x$ \\
\hline $\begin{array}{l}\text { Qualitative } \\
\text { telephone } \\
\text { interviews }\end{array}$ & & & & & & $x$ \\
\hline \multicolumn{7}{|l|}{ Intervention } \\
\hline GREAT Strides & & & $\mathrm{x}$ & $\mathrm{x}$ & $\mathrm{x}$ & \\
\hline
\end{tabular}

\section{Statistical analyses}


Recruitment, retention and data completeness rates were calculated using absolute (number of participants [n]) and relative (percentages [\%]) frequencies. Monthly recruitment rate was estimated using the mean and associated $95 \%$ confidence interval $(95 \% \mathrm{Cl})$. Demographic and clinical data are expressed as median (inter-quartile range [IQR]) for data that were not normally distributed, and absolute (n) and relative (\%) frequencies for nominal data. Intervention acceptability questionnaire item responses and adverse events (AEs) were analysed using absolute (n) and relative (\%) frequencies. Intervention adherence was analysed using the median (IQR) summary score for the EARS questionnaire.

\section{Primary outcome data}

In order to select the most appropriate instrument for subsequent project phases, an evaluation of measurement properties including minimal important difference (MID), longitudinal validity and responsiveness to change over 12 weeks was planned, subject to availability and completeness of study data. The MID was estimated by calculating the mean change score in participants who improved according to the CWA (anchor), minus the mean change score in participants who did not improve or whose symptoms worsened, with associated $95 \%$ Cls. Linear associations of change scores were determined between candidate outcome measures and the CWA using Pearson's correlation coefficient and $95 \%$ Cls. Responsiveness was to be evaluated using four different effect size statistics: the paired ttest, Cohen's d, standardised response mean (SRM) and the Guyatt index (GI) [67-70].

\section{Sample size}

An a priori sample size calculation was undertaken based on the evaluation of measurement properties of primary outcome candidates. A sample size of at least $n=42$ would allow detection of a magnitude of association (correlation coefficient) of at least 0.65 between the selected anchor (CWA) and outcome measures at $5 \%$ significance with $80 \%$ power, accounting for $20 \%$ attrition.

\section{Results}

\section{Demographics and clinical data}

Thirty-five participants were eligible and enrolled. Participant demographics are summarised in Table 3. Participants had a median (IQR) BMI of 26.6 (23.3-31.1), and the majority were in employment (63.6\%). Median (IQR) disease duration was 9.1 (4.0-16.2 months), in moderate DAS-28 disease activity states, and most were receiving disease modifying anti-rheumatic drugs (DMARDs) medication (88.6\%). 
Table 3

Baseline demographic and clinical characteristics.

\begin{tabular}{|ll|}
\hline Characteristic & Descriptive statistics \\
\hline Number of participants, $\mathrm{n}$ & 35 \\
\hline Age in years, median (IQR) & $60.1(49.4-68.4)$ \\
\hline Female sex, $\mathrm{n}(\%)$ & $24(68.6)$ \\
\hline BMI (Kg/m²), median (IQR) & $26.6(23.3-31.1)$ \\
\hline Primary employment status, $\mathrm{n}(\%)$ & \\
\hline Employed full-time & $11(33.3)$ \\
\hline Employed part-time & $8(24.2)$ \\
\hline Unemployed & $0(0.0)$ \\
\hline Self-employed & $2(6.1)$ \\
\hline Retired (because of age) & $8(24.2)$ \\
\hline Retired (because of ill health) & $2(6.1)$ \\
\hline Student & $0(0.0)$ \\
\hline Homemaker & $1(3.0)$ \\
\hline Other & $1(3.0)$ \\
\hline Ethnicity & \\
\hline British & $31(96.9)$ \\
\hline Indian & $2(5.7)$ \\
\hline Caribbean & $3(8.6)$ \\
\hline Any other white background & $1(3.1)$ \\
\hline Disease duration in months, median (IQR) & $9.1(4.0-16.2)$ \\
\hline DAS-28 median (IQR) & $4.0(3.1-4.6)$ \\
\hline Currently taking DMARDs & $31(88.6)$ \\
\hline Currently taking biologic drugs & $5(14.7)$ \\
\hline
\end{tabular}

\section{Intervention Feasibility \\ Intervention acceptability}


Twenty-three participants completed the intervention acceptability questionnaire at 12-week follow-up (Table 4). The intervention appeared to have excellent acceptability; $21 / 23$ (91.3\%) were confident that it could help the problem; $21 / 23(91.3 \%)$ reported that they would recommend it to a friend; $22 / 23(95.7 \%)$ indicated it made sense to them.

Table 4

Intervention Acceptability Questionnaire item responses at Visit 2 (Week 12).

\begin{tabular}{|c|c|c|}
\hline Item & Response & $\begin{array}{l}\mathrm{N} \text { (\%) } \\
\text { participants }\end{array}$ \\
\hline \multirow[t]{5}{*}{$\begin{array}{l}\text { Item 1: How confident are you that treatment can help the } \\
\text { problem? }\end{array}$} & $\begin{array}{l}\text { Not at all } \\
\text { confident }\end{array}$ & $0(0.0 \%)$ \\
\hline & $\begin{array}{l}\text { Not very } \\
\text { confident }\end{array}$ & $1(4.3 \%)$ \\
\hline & Neither & $1(4.3 \%)$ \\
\hline & Quite confident & $11(47.8 \%)$ \\
\hline & Very confident & $10(43.5 \%)$ \\
\hline \multirow[t]{5}{*}{$\begin{array}{l}\text { Item 2: Would you recommend the treatment to a friend with a } \\
\text { similar problem? }\end{array}$} & $\begin{array}{l}\text { Not at all } \\
\text { confident }\end{array}$ & $0(0.0 \%)$ \\
\hline & $\begin{array}{l}\text { Not very } \\
\text { confident }\end{array}$ & $1(4.3 \%)$ \\
\hline & Neither & $1(4.3 \%)$ \\
\hline & Quite confident & $8(34.8 \%)$ \\
\hline & Very confident & $13(56.5 \%)$ \\
\hline \multirow[t]{5}{*}{ Item 3: Does the treatment make sense to you? } & $\begin{array}{l}\text { Not at all } \\
\text { logical }\end{array}$ & $0(0.0 \%)$ \\
\hline & $\begin{array}{l}\text { Not very } \\
\text { logical }\end{array}$ & $0(0.0 \%)$ \\
\hline & No opinion & $1(4.3 \%)$ \\
\hline & Quite logical & $10(43.5 \%)$ \\
\hline & Very logical & 12 (52.2\%) \\
\hline
\end{tabular}

\section{Intervention Safety}

One participant reported mild transient post-exercise soreness which was an expected event of interest. One SAE was reported that was unrelated to the intervention or study participations . 
Twenty-three participants completed the EARS at 12-week follow-up (Figure 2), and a median (IQR) score of 17.5 (12.5-22.5) indicates good overall adherence to the intervention.

\section{Participant interview findings}

All but two of the 12 interview participants stated in the interview that they had continued with the intervention after the 12-week study period. Three global themes emerged from the data; intention and motivation, satisfaction of experience, and barriers to continuation which were aligned to relevant TFA constructs (Table 5). 
Table 5

Themes, TFA constructs and supportive narratives from participant interviews.

$\begin{array}{lll}\text { Themes } & \text { TFA } & \text { Supporting narrative } \\ & \text { Constructs } & \end{array}$

Intention Affective "I wanted to see what my limits were and so it was a no brainer to and attitude motivation

Satisfaction of experience
Perceived effectiveness give it a go" 010

"...it was at diagnosis that my whole world started to change...it created an opportunity to gain some control back" 009

"I am self-employed, so l've got to work, I've got to do it. So, it's in my interests to get myself as well as I can be" 003

"it was a challenge, but as I got on, I got faster and better at it and I was quite happy with that." 004

"Sometimes it's very easy to just sit. And having to do those, sort of got me going, got me moving." 001

"One of the tests where you had to put one foot in front of the other... I struggled with that as far as balance was concerned initially and the programme sort of improved that" 001

"... Once this [RA]came on, I couldn't do it [walking with friends]. Now, since I've gone on the gait project, I've started again, and l've done about three-or four-mile walks," 008

"... I feel my heart beating so it's got to be good for general fitness... I enjoy it and it lifts my mood' 010

"It doesn't work miracles overnight... it was a month and two weeks, that I could really see the difference" 004

"Obviously, I'm a bit stiff and it sort of limbers up a little bit, gets you going a little bit. I suppose it was just to get me moving" 006

Barriers to Burden continuation

"There's not space in the house, it's too small. I've only got my living room and my kitchen, and then the living room is only small, and it's got furniture and everything in it, so there's not ... and it's not safe to do anything, to be honest" 003

"Sometimes I'd do consecutive days and then miss a couple of days and other times I stuck to the three a week." 001

Opportunity costs

"Moving to a new house is an obstacle...But maybe once l've moved house and I've got less house work and gardening, I'm going to really go for it and I'm going to try and do it as often as possible...." 009

"... if I did do it at home I would find it difficult with the kids... its easier for me to go to a gym (after the hospital sessions)..." 010

Intention and motivation: There appeared to be a positive attitude as a character trait observed in all interview participants to try the intervention (affective attitude). This positive attitude emerged from determination and could have enabled adherence to the intervention. Most participants were seeking a 
solution and/or a challenge. For some, there were motivations towards being well enough to work as a result of doing the exercises.

Satisfaction of experience: Positive experiences of undertaking the exercises were described and perceived benefits appeared to maintain motivation (perceived effectiveness). Progression was apparent for the majority and a sense of achievement was described. There were perceptions of benefits amongst several participants such as improved movement ability, flexibility, balance, muscle strength, and resumption of social activity. Some participants highlighted negative experiences such as recurrence of previous injuries.

Barriers to continuation: Having enough space to carry out the intervention was one of the major issues identified (burden). However, participants acknowledged that the flexibility of the intervention was useful. Major life events such as moving to a new house and everyday responsibilities such as household chores were identified as main time sacrifices required to do the exercises (opportunity costs).

\section{Therapist interview findings}

Nine therapists (four physiotherapists, five podiatrists) participated in semi-structured interviews. Key barriers and enablers with regards to the acceptability of the training and intervention were identified (Table 6). Therapists liked the supportive training environment (affective attitude) and reported role play exercises aided confidence in applying MI and BCTs (self-efficacy). The lack of time available to attend training was considered problematic (opportunity costs). All therapists valued the opportunity to provide individualised care (intervention coherence). Barriers associated with acceptability included the use of trial-related materials (e.g. checklist) during intervention delivery (burden) and time delay between receiving training and intervention delivery (perceived effectiveness). 
Table 6

Themes, TFA constructs and supportive narratives from therapist interviews.

\section{TFA Supporting excerpts \\ Constructs}

\begin{tabular}{|c|c|c|}
\hline $\begin{array}{l}\text { Training } \\
\text { acceptability } \\
\text { barriers }\end{array}$ & $\begin{array}{l}\text { Opportunity } \\
\text { costs }\end{array}$ & $\begin{array}{l}\text { "In a busy NHS clinic, there's always pressure on patients and } \\
\text { waiting times, two days out of a clinic is a big ask it did have a } \\
\text { knock-on effect, and a potential impact on patient care" (01_002) }\end{array}$ \\
\hline \multirow{3}{*}{$\begin{array}{l}\text { Training } \\
\text { acceptability } \\
\text { enablers }\end{array}$} & $\begin{array}{l}\text { Affective } \\
\text { attitude }\end{array}$ & "it was a really nice small, friendly, informal environment" (03_003) \\
\hline & $\begin{array}{l}\text { Perceived } \\
\text { effectiveness }\end{array}$ & $\begin{array}{l}\text { "The packaging that we got was excellent, there wasn't anything that } \\
\text { was left out, I actually refer to training materials a lot in clinic, } \\
\text { everything was really well done"(03_004) }\end{array}$ \\
\hline & Self-efficacy & $\begin{array}{l}\text { "I felt confident doing the MI practice because I've had training } \\
\text { before"(03_003) }\end{array}$ \\
\hline
\end{tabular}

Intervention Burden "It definitely felt like there's a lot of paperwork. Putting it all together delivery in a sequence with all the paperwork in front of you... that felt like acceptability there was quite a lot to do for one appointment"(03_003)

barriers

\begin{tabular}{|c|c|c|}
\hline \multirow[t]{2}{*}{$\begin{array}{l}\text { Intervention } \\
\text { delivery } \\
\text { acceptability } \\
\text { enablers }\end{array}$} & $\begin{array}{l}\text { Intervention } \\
\text { coherence }\end{array}$ & $\begin{array}{l}\text { "The follow-up sessions were good to check if we'd changed } \\
\text { something in the second consultation and l just wanted to make } \\
\text { sure that they were managing the alterations that we'd agreed and } t \\
\text { make sure that they were happy in what they were doing" (03_001) }\end{array}$ \\
\hline & $\begin{array}{l}\text { Perceived } \\
\text { effectiveness }\end{array}$ & $\begin{array}{l}\text { "The ones that were motivated and committed to it and did it, were } \\
\text { thrilled at how quickly they started to pick up the exercises. They } \\
\text { could see the changes in themselves, so, it definitely is effective" } \\
\text { (02_001) }\end{array}$ \\
\hline
\end{tabular}

\section{Intervention fidelity}

Four physiotherapists and two podiatrists delivered 78 GREAT Strides sessions across three centres in the UK (see Additional File 4). Audio recordings of the GREAT Strides intervention for 28 participants across 64 sessions were considered for the assessment of fidelity. A sample of $37(50 \%)$ of sessions 1-6 delivered across the three sites were coded for MITI delivery. Good inter-rater reliability was achieved, $73 \%$ (Cl 0.68-0.78). Relational (mean [SD] 4.38 [0.844]) and technical (mean [SD] 4.19 [0.837]) aspects of MI were delivered with proficiency. Data from 28 participants across 55 sessions were rated for core components and BCTs. The 6 core components and 7 BCTs in Session 1 were delivered with high ( $\geq 80 \%)$ treatment fidelity but 10 further BCTs were not consistently delivered. In session 2, 4 core components and 4 BCTs were delivered with high fidelity, but another 8 BCTs were not consistently delivered. In session 3 three core components and 2 BCTs were delivered consistently. In session 4, 3 core components were delivered with high fidelity, but none of the 12 BCTs were delivered consistently. For sessions 5 and 6 , only 2 core components were delivered consistently, with 6 out of 12 BCTs for session 5 being delivered with high fidelity, and 2 BCTs out of 12 being delivered with high fidelity for session 6 


\section{Evaluation of future randomised trial feasibility \\ Primary outcome measure candidates' evaluation}

Mean change scores and associated effect sizes for estimating responsiveness are presented in Table 7 for the 15 participants who had complete data. Participants' perceptions of change in walking ability at 12 weeks are presented in Figure 3. Change scores for outcome measures were all in the expected direction (improvement). Effect sizes were within the small to medium range. The PROMIS-PF-20 and ROAD-les appeared to be modestly more responsive relative to the FFI-DS and 10MWT.

Table 7

Change scores summarised for primary outcome measure candidates.

\begin{tabular}{|lllll|}
\hline & Mean change 12 weeks & T-statistic (p-value) & Cohen's D (95\% Cl) & SRM \\
\hline FFI-DS & -4.14 & $-1.07, p=0.296$ & $0.24(-0.22,0.69)$ & -0.22 \\
\hline PROMIS-PF-20 & 1.85 & $2.59, p=0.017$ & $-0.28(-0.50,-0.06)$ & 0.54 \\
\hline ROAD-les & -0.79 & $-2.36, p=0.028$ & $0.44(0.05,0.84)$ & -0.49 \\
\hline 10MWT in seconds & -2.75 & $-1.03, p=0.316$ & $0.23(-0.23,0.70)$ & -0.21 \\
\hline $\begin{array}{l}\text { The mean change from baseline summarised for the candidate primary outcome measures for those } \\
\text { with complete outcome data at baseline and 12-week visits. Responsiveness statistics presented } \\
\text { include the paired T-test statistic (and p-value), Cohen's D (95\% Cl) and the Standardised Response } \\
\text { Mean (SRM). }\end{array}$ \\
\hline
\end{tabular}

Missing data for the CWA score and observed distributions across ordered categories of the Likert scale limited our ability to perform a priori planned analyses. For the 15 participants who completed all outcome measures at 12 weeks, results suggest that the FFI-DS, PROMIS PF-20 and 10MWT measures performed best in terms of theoretical consistency, direction of change and longitudinal validity (Tables 7 and 8). The ROADles lacked theoretical consistency as a greater improvement was observed in those classed as "not improved" relative to "improved" according to the CWA (Table 8 and Additional File 5). 
Table 8

Mean change according to CWA improvement for primary outcome measure candidates.

\begin{tabular}{|llllll|}
\hline $\begin{array}{l}\text { Outcome } \\
\text { measure }\end{array}$ & $\begin{array}{l}\text { All } \\
(\mathbf{n}=15)\end{array}$ & $\begin{array}{l}\text { Improved } \\
(\mathbf{n}=12)\end{array}$ & $\begin{array}{l}\text { Not } \\
\text { improved } \\
(\mathbf{n}=3)\end{array}$ & $\begin{array}{l}\text { Mean difference improvers versus } \\
\text { non-improvers (95\% Cl) }\end{array}$ & $\mathbf{r}$ \\
\hline FFI-DS & -2.27 & -2.63 & -0.8 & $-1.83(-32.58,28.92)$ & -0.12 \\
\hline $\begin{array}{l}\text { PROMIS } \\
\text { PF-20 }\end{array}$ & 1.69 & 1.8 & 1.23 & $0.57(-6.24,7.37)$ & 0.16 \\
\hline ROADIes & -0.75 & -0.73 & -0.83 & $0.10(-2.35,2.56)$ & 0.17 \\
\hline 10MWT & -0.91 & -1.03 & -0.43 & $-0.60(-2.42,1.22)$ & -0.28 \\
\hline
\end{tabular}

\section{Recruitment, retention and data completeness}

Recruitment ran from June 2018 to March 2019, and follow-ups were completed July 2019. A total of 340 patients were screened and 35 participants were identified as eligible and enrolled (Figure 4). Monthly participant recruitment rate was $3.5(95 \% \mathrm{Cl} ; 2.46,4.79)$. Twelve participants withdrew from the study, of which 6 were lost to follow-up. The mean (SD) time from baseline to study withdrawal was 80 (49.9) days. Four participants stated they were unwilling to continue in the study, and 1 was unable to complete the intervention. A total of $23(65.7 \%)$ participants completed follow up at 12 weeks from baseline. All 23 participants completed all outcome measures $(n=23,100 \%)$ with the exception of the CWA scale, which was completed by 15 participants ( $n=8,34 \%$ missing).

\section{Discussion}

The results of this study found that the GREAT Strides programme was viewed as acceptable by patients and therapists, and was delivered with good Ml proficiency and high core components fidelity, good patient adherence and no safety concerns. Some adaptations to the intervention and therapist training are required to optimise delivery of BCTs.

The feasibility of a future randomised trial included identification and justification of a suitable primary outcome measure, somewhat acceptable recruitment rates and data completeness were demonstrated but refinements are required.

\section{Intervention acceptability}

The acceptability of the intervention amongst participants was high. This was largely corroborated by our interview findings. These positive findings appear to be driven initially by a positive affective attitude character trait and a willingness to try to improve and regain control, and subsequently experiences of perceived effectiveness of the intervention which was also reflected by therapists. These findings were encouraging given the reported variable success of interventions involving behaviour change for 
promoting exercise and physical activity [71]. References to perceived improvements in key therapeutic targets that the intervention was designed to address such as improved mobility, balance and strength provide further intervention credibility. Whilst there was no explicit mention of the behaviour change techniques that were embedded within the delivery of GREAT Strides, qualitative explorations suggest that participants may have experienced improved self-efficacy and ability to overcome barriers to completion. Indeed, interventions which enable barriers to exercise and physical activity to be overcome have been identified as essential to help sustain behaviour change [23]. However, some barriers to completion were identified.

Intervention training was largely viewed as a positive experience by therapists. Previous experience of MI and a desire integrate psychological approaches into practice appeared to result in greater confidence in intervention delivery. The training content and delivery was described as comprehensive but the requirement to attend two face-to-face sessions and time pressures were identified. In isolated cases, there was a gap between completion of training and first delivery of the intervention, which needs to be addressed where possible. Future therapist training has been refined to be delivered online and, includes self-directed learning, synchronous online practice sessions with support, and refinement of therapist support materials.

Intervention delivery was considered to be coherent and perceived as effective amongst therapists. However, some challenges were identified concerning the need for follow-up appointments within a 2week timeframe for therapists with busy caseloads, and the burden of paperwork required.

\section{Safety and adherence}

The intervention was well tolerated by participants, with only one report of an SAE unrelated to the intervention, and one report of an expected adverse event (AE) of post-intervention soreness. These findings were largely corroborated by the qualitative exploration where reference is made to some postintervention ankle soreness (one participant with a previous history of an ankle injury), and additional reference to possible safety concerns where there was a lack of sufficient floor-space at home. These findings agree with recent evidence suggesting walking exercise programmes for people with early and established RA appear to be well tolerated $[72,73]$.

\section{Adherence}

Good adherence to the intervention was demonstrated, with a median EARS score of 17 from a possible 24. Interpretation of this score is difficult due to a lack of comparable UK data from the early RA population, however recent research from Brazil and Nepal suggest cut-off scores of 17 and 17.5 respectively to discriminate adherent and non-adherence participants with respect to prescribed exercise $[74,75]$.

\section{Intervention fidelity}

The fidelity assessment methods proved to be appropriate, successful and therefore suitable for use in a future trial. Clinicians were able to deliver the most components of GREAT-Strides (MI, all core 
components and some BCTs) with high fidelity. However, not all BCTs were delivered with high fidelity. The intervention will be simplified to specify mandatory and optional BCTs, depending on needs of individual participants, as previous research shows interventions with seven or fewer BCTs may be more effective at enhancing adherence [76]. Fidelity results and clinician interviews have enabled training refinement, including demonstration videos to support therapists deliver the intervention. Results also suggest that tailoring the training accounting for prior experience in delivering MI may be required.

\section{Primary outcome measures}

Results of the analyses of the primary outcome candidates were considered by the Trial Management Group in order to recommend which measure would be taken forward to a future main trial. Similarities were observed across the 3 of the 4 primary outcome measure candidates in terms of their responsiveness and theoretical consistency in terms of anticipated direction and magnitude of change over time. The ROADles was not recommended for the future main trial due to its lack of theoretical consistency. Given the similarities observed for the 3 remaining measures, practicalities and relative simplicity of measures were considered as recommended by the COnsensus-based Standards for the selection of health Measurement INstruments (COSMIN) [77]. The 10MWT was identified as having additional practical implications, requiring face to face assessment with sufficient floor space. The PROMIS-PF-20 performed well overall in terms of measurement properties, but issues were identified with the additional steps required for scoring (conversion to t-scores) prior to analysis and concerns raised regarding interpretability. Therefore, the FFI-DS was preferred due to its largely desirable measurement properties, ease of completion and scoring, widespread use, and clinical relevance.

\section{Recruitment and retention}

Despite high prevalence of foot disease and impaired lower limb function in early RA, our recruitment rate for the GREAT Strides programme was lower than anticipated, with an average of 3.5 participants per month. Poor enrolment and attrition rates have been reported in other feasibility studies involving behaviour change in this population [78]. Through evaluation of screening logs and dialogue with site personnel, we established one of the limiting factors was confirmation of meeting ACR 2010 classification criteria for RA, which is often not recorded in routine care and the inclusion criterion for the future main trial will be amended so that patients with a clinician diagnosis of RA can be included.

The prevalence of disease-related foot and ankle involvement and thus the pool of potentially eligible participants appeared to be far lower than anticipated. As a result, we anticipate that more recruitment sites will be required for the future main trial to achieve desired recruitment rates. Moreover, the mailshot approach to recruitment appears to be an essential component of the recruitment strategy to supplement recruitment from the rheumatology outpatients setting. Recruitment initially took place in "early arthritis" clinics only, where patients in the first year following their RA diagnosis were being seen by clinicians. Such patients are coming to terms with a life changing diagnosis and experience a high volume of clinical appointments to control inflammatory disease activity, and therefore may be less likely to agree to 
participate in research. Future recruitment will be extended to established RA clinics in order to identify additional potentially eligible participants within two years' post-diagnosis.

Attrition rate was higher than anticipated at $34.3 \%$. The reasons for this remain largely unclear, as the majority of participant attritions were lost to follow-up without giving a reason $(n=6)$. This feasibility study necessitated in-person follow-ups for collection of the performance-based outcome measure 10MWT at 12 weeks. However, with refinement of outcome measures, these could be collected remotely which may improve retention and data completeness. The addition of short message service reminders could also improve follow-up adherence [79]. In addition, based on the number of GREAT intervention sessions delivered in the feasibility phase, where only one patient received sessions five and six, reducing the intervention to two compulsory plus further two optional sessions seems sufficient.

\section{Conclusions}

GREAT Strides was viewed as acceptable by patients and therapists, was mostly delivered as intended, with good patient adherence and no safety concerns. Recommendations are provided for primary outcome selection for a future trial. Recruitment and attrition rates may improve with refinement of the intervention, follow-up procedures and eligibility criteria, and should be further evaluated via a pilot trial.

\section{Abbreviations}

10MWT: 10-metre walk test

ACR: American College of Rheumatology

AE: Adverse event

BCT: Behaviour change technique

BMl: Body mass index

Cl: Confidence interval

COSMIN: COnsensus-based Standards for the selection of health Measurement INstruments

CWA: Change in walking ability

DAS-28: Disease activity score 28

DMARD: Disease modifying anti-rheumatic drugs

DVD: Digital versatile disc

EARS: Exercise adherence rating scale 
FFI-DS: Foot function index disability subscale

Gl: Guyatt index

GREAT: Gait rehabilitiation in early arthritis trial

IQR: Inter-quartile range

Ml: Motivational interviewing

MID: Minimal important difference

MITI: Motivational interviewing treatment integrity scale

MRC: Medical Research Council

NHS: National Health Service

PPI: Patient and public involvement

PROMIS PF-20: Patient Reported Outcome Measurement Information System Physical Function Short Form

RA: Rheumatoid arthritis

ROADles: Recent-Onset Arthritis Disability lower extremity subscale

RPE: Rating of perceived exertion

SAE: Serious adverse events

SD: Standard deviation

SPIRIT Standard Protocol Items: Recommendations for Interventional Trials

SRM: Standardised response mean

TBP: Theory of planned behaviour

TFA: Theoretical framework of acceptability

\section{Declarations}

\section{Ethics approval and consent to participate}

This feasibility study was reviewed and approved by the West of Scotland Research Ethics Committee 3 (17/WS/0264) in January 2017. 


\section{Consent for publication}

Not applicable

\section{Availability of data and materials}

The data that support the findings of this study are available from the corresponding author pending reasonable request

\section{Competing interests}

\section{Funding}

This feasibility study was funded by the NIHR Health Technology Assessment Programme (15/165/04).

\section{Authors' contributions}

MPMS is the chief investigator of the project and along with GJH developed the initial project proposal idea. $L B, N E F, E G, S H, H M, A M, I M, C S, M v d L, A E W$ and JW were grant holders and helped refine the proposal and subsequent protocol. LJ worked as the project co-ordinator and helped translate the proposal into a protocol. AP and MS worked as research associates and helped to develop the intervention and therapist training. EG and MS led intervention fidelity evaluations and therapists' qualitative component. AEW led the participants' qualitative component. AM and BS undertook statistical analyses and reporting. GJH, AP and MPMS drafted the manuscript. All authors have read and approved the final manuscript.

\section{Acknowledgements}

The authors would like to acknowledge the independent Study Steering Committee for their contributions to supporting the project: Shea Palmer, Denise Howel, Andrew Lemmey, Peter Heine, Emma Stanmore, Caroline Flurey, and Maureen McAllister. We would also like to acknowledge our Patient and Public Involvement partners Harry Ramsay and Maureen McLure for their essential involvement in the early stages of intervention development and contributions to reviewing patient facing study documents and intervention support materials. We would like to acknowledge research staff at feasibility study sites for their contributions in supporting the study locally: Lucy Huckfield, Amy Thompson, Gary Semple, and Dominic Rimmer. We would like to acknowledge the contributions by Aliya Amirova and Lucy Harding for undertaking ratings of audio recordings for the intervention fidelity assessment. Finally, we wish to acknowledge all of the participants and therapists who took part in the study.

\section{References}

1. National Audit Office. Services for people with rheumatoid arthritis.2009. 
2. Grondal L, Tengstrand B, Nordmark B, Wretenberg P, Stark A. The foot: still the most important reason for walking incapacity in rheumatoid arthritis: distribution of symptomatic joints in 1,000 RA patients. Acta Orthop 2008;79:257-261.

3. Michelson J, Easley M, Wigley FM, Hellma D. Foot and ankle problems in rheumatoid arthritis. Foot Ankle Int 1994;15:608-13.

4. van der Leeden M, Steultjens MP, Ursum J, Dahmen R, Roorda LD, Schaardenburg DV, Dekker J. Prevalence and course of forefoot impairments and walking disability in the first eight years of rheumatoid arthritis. Arthritis Rheum 2008;59:1596-1602.

5. Carrol M, Parmar P, Dalbeth N, Boocock M, Rome K. Gait characteristics associated with thefoot and ankle in inflammatory arthritis: a systematic review and meta-analysis. BMC MSK Disorders 2015,16:134.

6. Baan H, Dubbeldam R, Nene AV, van de Laar MAFJ. Gait analysis of the lower limb in patients with rheumatoid arthritis: a systematic review. Semin Arthritis Rheum 2012,41:768-788.

7. Weiss RJ, Wretenberg P, Stark A, Palmblad K, Larsson P, Grondal L, Brostrom E. Gait pattern in rheumatoid arthritis. Gait \& Posture 2008,28:229-234.

8. Paul L, Rafferty D, Marshall-McKenna R, Gill JMR, Mclnnes I, Porter D, Woodburn J. Oxygen cost of walking, physical activity and sedentary behaviours in rheumatoid arthritis. Scan J Rheumatol 2014;43:28-34.

9. Piva SR, Almeida GJM, Wasko MCM. Association of physical function and physical activity in women with rheumatoid arthritis. Arthrit Care Res 2010;62:1144-51.

10. Lemmey AB, Marcora SM, Chester K, Wilson S, Casanova F, Maddison PJ. Effects of high intensity resistance training in patients with rheumatoid arthritis: a randomized controlled trial. Arthritis Rheum 2009;61:1726-34.

11. Tourinho TF, Capp E, Brenol JC, Stein A. Physical activity prevents bone loss in premenopausal women with rheumatoid arthritis: a cohort study. Rheumatol Int 2008;28:1001-7.

12. Metsios GS, Stavropoulos-Kalinoglou A, Panoulas VF, Wilson M, Nevill AM, Koutedakis $Y$, et al. Association of physical inactivity with increased cardiovascular risk in patients with rheumatoid arthritis. J Cardiovasc Risk 2009;16:188-94.

13. Turesson C, Matteson EL. Cardiovascular risk factors, fitness and physical activity in rheumatic diseases. Curr Opin Rheumatol 2007;19:190-6.

14. Sattar N, Mclnnes IB. Vascular comorbidity in rheumatoid arthritis: potential mechanisms and solutions. Curr Opin Rheumatol 2005;17:286-92.

15. Wilkinson TJ, Lemmey AB, Jones JG, Sheikh F, Ahmad YA, Chitale S, Maddison PJ, O’Brien TD. Can creatine supplementation improve body composition and objective physical function in rheumatoid arthritis patients? A randomised controlled trial. Arthritis Care Res 2016;68:729-37.

16. Challal S, Minichiello E, Boissier MC, Semerano L. Cachexia and adiposity in rheumatoid arthritis. Relevance for disease management and clinical outcomes. Joint Bone Spine 2016;83:127-33. 
17. Lusa AL, Amigues I, Kramer HR, Dam T-T, Giles JT. Indicators of walking speed in rheumatoid arthritis: relative influence of articular, psychosocial, and body composition characteristics. Arthritis Care \& Research 2015,67;1:21-31.

18. Kramer HR, Fontaine KR, Bathon JM, Giles JT. Muscle density in rheumatoid arthritis: associations with disease features and functional outcomes. Arthritis \& Rheumatism 2012,64;8:2438-2450.

19. Giles JT, Bartlett SJ, Fontaine KR, Bathon JM. Association of body composition with disability in rheumatoid arthritis: impact of appendicular fat and lean tissue mass. Arthritis Rheum 2008,59;10:1407-1415.

20. Marcora SM, Chester KR, Mittal G, Lemmey AB, Maddison PJ. Randomized phase 2 trial of anti-tumor necrosis factor therapy for cachexia in patients with early rheumatoid arthritis. Am J Clin Nutr 2006;84:1463-72.

21. Rome K, Dixon J, Gray M, Woodley R. Evaluation of static and dynamic postural stability in established rheumatoid arthritis: exploratory study. Clinical Biomechanics 2009;24:524-6.

22. Morpeth T, Brenton-Rule A, Carroll M, Frecklington M, Rome K. Fear of falling and foot pain, impairment and disability in rheumatoid arthritis: a case-control study. Clinical Rheumatology 2015: DOI 10.1007/s10067-015-3124-6.

23. Van Zanten JJCSV, Rouse PC, Hale ED, Ntoumanis N, Metsios GS, Duda JL, Kitas GD. Perceived barriers, facilitators and benefits for regular physical activity and exercise in patients with rheumatoid arthritis: a review of the literature. Sports Medicine 2015,45:1401-1412.

24. Nordgren B, Friden C, Demmelmaier I, Opava CH. Who makes it to the base? Selection procedure for a physical activity trial targeting people with rheumatoid arthritis. Arthritis Care Res 2014;66:662-670.

25. Brenton-Rule A, D'Almeida S, Bassett S, Carroll M, Dalbeth N, Rome K. The effects of sandals on postural stability in patients with rheumatoid arthritis: an exploratory study. Clinical Biomechanics 2014;29:350-353.

26. Turner DE, Helliwell PS, Emery P, Woodburn J. The impact of rheumatoid arthritis on foot function in the early stages of disease: a clinical case series. BMC Musculoskeletal Disorders 2006, 7:102.

27. Vervloesem N, van Gils N, Ovaere L, Westhovens R, van Assche D. Are personal characteristics associated with exercise participation in patients with rheumatoid arthritis? A cross-sectional explorative survey. Musculoskeletal Care 2012;10:90-100.

28. Crowley L, Kennedy N. Barriers to exercise in rheumatoid arthritis - a focus group study. Physiotherapy Practice and Research 2009;30:27-33.

29. Wilcox S, Der AC, Abbott J, et al. Perceived exercise barriers, enablers, and benefits among exercising and non exercising adults with arthritis: results from a qualitative study. Arthritis Rheum 2006,55;4:616-27.

30. Martin ES, Dobson F, Hall M, Marshall C, Egerton T. The effects of behavioural counselling on the determinants of health behaviour change in adults with chronic musculoskeletal conditions making lifestyle changes: A systematic review and meta-analysis. Musculoskeletal Care. 2019;17:170-197. 
31. Mehrholz J, Kugler J, Storch A, PohIM,Hirsch K, Elsner B. Treadmill training for patients with Parkinson's disease. Cochrane Database of Systematic Reviews 2015, Issue 9. Art. No.:CD007830.

32. Mehrholz J, Pohl M, Elsner B. Treadmill training and body weight support for walking after stroke. Cochrane Database Syst Rev 2014;1:Cd002840 doi:10.1002/14651858.CD002840.pub3.

33. Mehrholz J, Elsner B, Werner C, et al. Electromechanical-assisted training for walking after stroke. Cochrane Database Syst Rev 2013;7:Cd006185 doi:10.1002/14651858.CD006185.pub3.

34. Mehrholz J, Kugler J, Pohl M. Locomotor training for walking after spinal cord injury. Cochrane Database of Systematic Reviews 2012, Issue 11. Art. No.: CD006676.

35. Mehrholz J, Friis R, Kugler J, et al. Treadmill training for patients with Parkinson's disease. Cochrane Database Syst Rev 2010(1):Cd007830.

36. Hollands KL, Pelton TA, Wimperis A, Whitham D, Tan W, Jowett S, Sackley CM, Wing AM, Tyson SF, Mathias J, Hensman M, van Vliet PM. Feasibility and preliminary efficacy of visual cue training to improve adaptability of walking after stroke. Multi-centre, single-blind randomised control pilot trial. PLoS ONE 2015;10: e0139261.

37. da Silva KNG, de Paiva Teixeira LEP, Imoto AM, Atallah AN, Peccin MS, Trevisani VFM. Effectiveness of sensorimotor training in patients with rheumatoid arthritis: a randomized controlled trial. Rheumatol Int 2012,33:2269-2275.

38. Williams SB, Brand CA, Hill KD, Hunt SB, Moran H. Feasibility and outcomes of a homebased exercise program on improving balance and gait stability in women with lower-limb osteoarthritis or rheumatoid arthritis: a pilot study. Arch Phys Med Rehabil 2010,91:106-114.

39. Craig P, Dieppe P, Macintyre S, Michie S, Nazareth I, Petticrew M. Developing and evaluating complex interventions: the new Medical Research Council guidance. BMJ. 2008;337:a1655.

40. O'Cathain A, Croot L, Duncan E, Rousseau N, Sworn K, Turner KM, Yardley L, Hoddinott P. Guidance on how to develop complex interventions to improve health and healthcare. BMJ Open 2019; 9:e029954.

41. Aletaha D, Neogi T, Silman AJ, Funovits J, Felson DT, Bingham CO 3rd, Birnbaum NS, Burmester GR, Bykerk VP, Cohen MD, Combe B, Costenbader KH, Dougados M, Emery P, Ferraccioli G, Hazes JM, Hobbs K, Huizinga TW, Kavanaugh A, Kay J, Kvien TK, Laing T, Mease P, Ménard HA, Moreland LW, Naden RL, Pincus T, Smolen JS, Stanislawska-Biernat E, Symmons D, Tak PP, Upchurch KS, Vencovský J, Wolfe F, Hawker G. 2010 Rheumatoid arthritis classification criteria: an American College of Rheumatology/European League Against Rheumatism collaborative initiative. Arthritis Rheum. 2010;62:2569-81.

42. Campbell AJ, Robertson MC, Gardner MM, Norton RN, Tilyard MW, Buchner DM. Randomised controlled trial of a general practice programme of home based exercise to prevent falls in elderly women. BMJ 1997;315:1065-9.

43. Campbell AJ, Robertson MC, Gardner MM, Norton RN, Buchner DM. Psychotropic medication withdrawal and a home-based exercise program to prevent falls: a randomised, controlled trial. J Am Geriatr Soc 1999;47:850-3. 
44. Robertson MC, Devlin N, Gardner MM, Campbell AJ. Effectiveness and economic evaluation of a nurse delivered home exercise programme to prevent falls. 1: Randomised controlled trial. BMJ 2001;322:697-701.

45. Robertson MC, Gardner MM, Devlin N, McGee R, Campbell AJ. Effectiveness and economic evaluation of a nurse delivered home exercise programme to prevent falls. 2: Controlled trial in multiple centres. BMJ 2001;322:701-4.

46. Miller WR, Rollnick S. Motivational interviewing: preparing people for change. 2002. New York: Guilford Press.

47. Miller WR, Rollnick S. Meeting in the middle: motivational interviewing and self determination theory. International Journal of Behavioural Nutrition and Physical Activity 2012;9:25.

48. Ajzen I. The theory of planned behaviour. Organ Behav Hum Dec Process 1991,50:179-211.

49. Ajzen I, Madden TJ. Prediction of goal-directed behaviour: attitudes, intentions, and perceived behavioral control. Journal of Experimental Social Psychology 1986;22:453-74.

50. Ajzen I, Sheikh S. Action versus inaction: anticipated affect in the theory of planned behaviour. Journal of Applied Social Psychology 2013,43:155-162.

51. Manning VL, Hurley MV, Scott DL, Coker B, Choy E, Bearne LM. Education, self-management, and upper extremity exercise training in people with rheumatoid arthritis: a randomised controlled trial. Arthritis Care Res 2014;66:217-27.

52. Borg G. Perceived exertion as an indicator of somatic stress. Scand J Rehabil Med 1970;2:92-8.

53. The Gait Rehabilitation in Early Arthritis Trial website. www.great-trial.co.uk. Accessed 25 August 2021.

54. Foster NE, Thomas E, Barlas P, Hill JC, Young J, Mason E, Hay EM. Acupuncture as an adjunct to exercise based physiotherapy for osteoarthritis of the knee: randomised controlled trial. BMJ 2007; doi:10.1136/bmj.39280.509803.BE.

55. Vincent CA, Lewith G. Placebo controls for acupuncture studies. J R Soc Med 1995;88:199-202.

56. Naomi A. Newman-Beinart, Sam Norton, Dominic Dowling, Dimitri Gavriloff, Chiara Vari, John A. Weinman, Emma L. Godfrey. The development and initial psychometric evaluation of a measure assessing adherence to prescribed exercise: the Exercise Adherence Rating Scale (EARS). Physiotherapy 2017;103(2):180-185.

57. Attride-Stirling J. Thematic networks: an analytic tool for qualitative research. Qualitative Research 2001;1:385-405.

58. Sekhon M, Cartwright M, Francis JJ. Acceptability of healthcare interventions: an overview of reviews and development of a theoretical framework. BMC Health Services Research 2017;17:88.

59. Moyers TB, Martin T, Manuel JK, Hendrickson SML, Miller WR. Assessing competence in the use of motivational interviewing. Journal of Substance Abuse Treatment 2005,28:19-26.

60. Michie S, Richardson M, Johnstone M, Abraham C, Francis J, Hardeman W, Eccles MP, Came J, Wood CE. The behavior change technique taxonomy (v1) of 93 hierarchically clustered techniques: building 
an international consensus for the reporting of behavior change interventions. Ann Behav Med 2013;46(1):81-95.

61. Budiman-Mak E, Conrad KJ, Roach KE. The foot function index: a measure of foot pain and disability. J Clin Epidemiol. 1991;44:561-570.

62. Hays RD, Spritzer KL, Fries JF, Krishnan E. Responsiveness and minimally important difference for the patient-reported outcomes measurement and information system (PROMIS ${ }^{\circledR}$ ) 20-item physical functioning short-form in a prospective observational study of rheumatoid arthritis. Ann Rheum Dis 2015,74;1:104-107.

63. Salaffi F, Stancati A, Neri R, Grassi W, Bombardieri S. Measuring functional disability in early rheumatoid arthritis: the validity, reliability and responsiveness of the recent-onset arthritis disability (ROAD) index. Clinical and Experimental Rheumatology 2005;23:S31-42.

64. Ward MM. Clinical measures in rheumatoid arthritis: which are most useful in assessing patients? Journal of Rheumatology 1994;21:17-27.

65. Spiegel JS, Paulus HE, Ward NB, Spiegel TM, Leake B, Kane RL. What are we measuring? An examination of walk time and grip strength. Journal of Rheumatology 1987;14:80-6.

66. Revicki D, Hays RD, Cella D, Sloan J. Recommended methods for determining responsiveness and minimally important differences for patient-reported outcomes. Journal of Clinical Epidemiology 2008;61:102-109.

67. Menz HB, Auhl M, Ristevski S, Frescos N, Munteanu SE. Comparison of the responsiveness of the Foot Health Status Questionnaire and the Manchester Foot Pain and Disability Index in older people. Health and Quality of Life Outcomes 2014;12:158.

68. Crosby RD, Kolotkin RL, Williams GR: Defining clinically meaningful change in health-related quality of life. J Clin Epidemiol 2003, 56:395-407.

69. Beaton DE: Understanding the relevance of measured change through studies of responsiveness. Spine 2000, 25:3192-3199.

70. Husted JA, Cook RJ, Farewell VT, Gladman DD: Methods for assessing responsiveness: a critical review and recommendations. J Clin Epidemiol 2000, 53:459-468.

71. Larkin L, Kennedy N, Gallagher S. Promoting physical activity in rheumatoid arthritis: a narrative review of behaviour change theories, Disability and Rehabilitation 2015,37;25:2359-2366.

72. Bartlett DB, Willis LH, Slentz CA, Hoselton A, Kelly L, Huebner JL, Kraus VB, Moss J, Muehlbauer MJ, Spielmann G, Kraus WE, Lord JM, Huffman KM. Ten weeks of high-intensity interval walk training is associated with reduced disease activity and improved innate immune function in older adults with rheumatoid arthritis: a pilot study. Arthritis Research \& Therapy 2018;20:127.

73. Baxter SV, Hale LA, Stebbings S, Gray AR, Smith CM, Treharne GJ. Walking is a feasible physical activity for people with rheumatoid arthritis: a feasibility randomized controlled trial. Musculoskeletal Care $2015 ;$ 14(1):47-56.

74. Lira MR, Anamaria SO, Franca RA, Pereira AC, Godfrey EL, Chaves TC. The Brazilian Portuguese version of the Exercise Adherence Rating Scale (EARS-Br) showed acceptable reliability, validity and 
responsiveness in chronic low back pain. BMC Musculoskeletal Disorders 2020;21:294.

75. Adhikari SP, Dev R, Shrestha JN. Cross-Cultural Adaptation and Validation of the Exercise Adherence Rating Scale to Nepali language: A Methodological Study. Health and Quality of Life Outcomes 2020;18:328.

76. Meade L, Bearne L, Sweeney L, Alageel S and Godfrey E. Behaviour change techniques associated with adherence to prescribed exercise in patients with persistent musculoskeletal pain: Systematic review. British Journal of Health Psychology 2018;24(1):10-30.

77. Prinsen CAC, Mokkink LB, Bouter LM, Alonso J, de Vetr HCW, Terwee CB. COSMIN guideline for systematic reviews of patient reported outcome measures. Quality of Life Research 2018;27:11471157.

78. Garner S, Fenton T, Martin L, Creaser C, Johns C, Barnabe C. Personalized diet and exercise recommendations in early rheumatoid arthritis: a feasibility trial. Musculoskeletal Care 2018;16(1):167-172.

79. Lin H, Wu X. Intervention strategies for improving patient adherence to follow-up in the era of mobile information technology: a systematic review and meta-analysis. PLOS One 2014;9(8):e104266.

\section{Figures}


1.

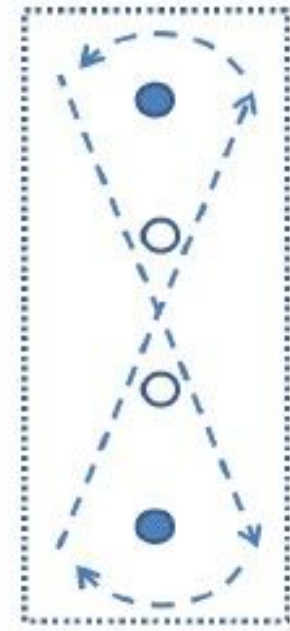

4.

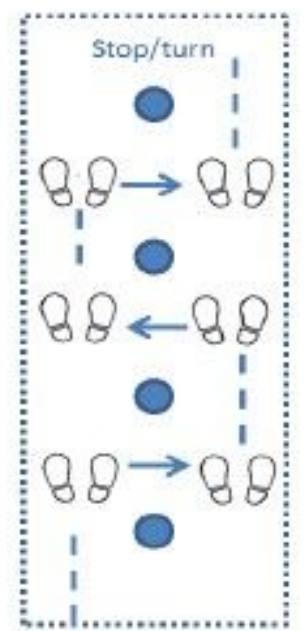

2.

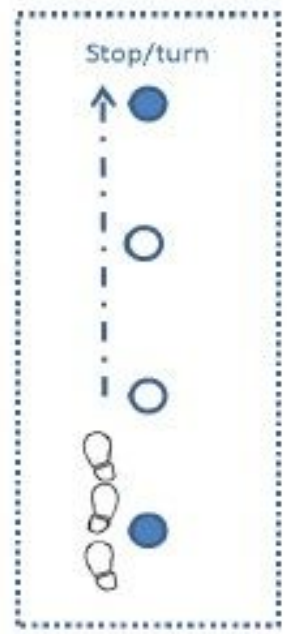

5.

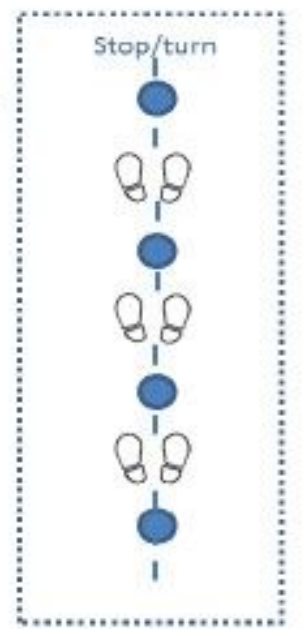

3.

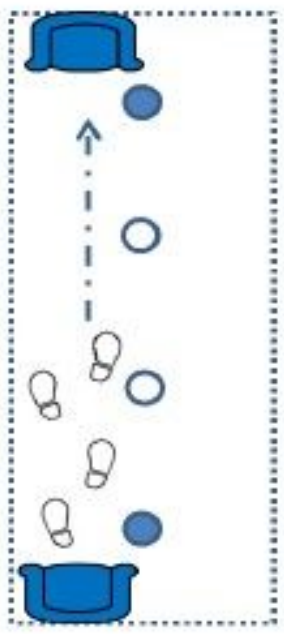

6.

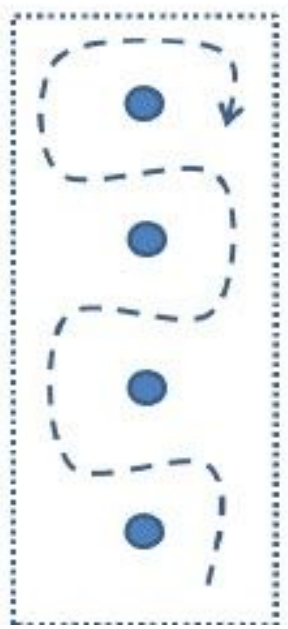

Figure 1

GREAT Strides gait rehabilitation circuit; 1) figure of 8 walk, 2) heel-to-toe walk, 3) get up and go, 4) obstacle side-step, 5) obstacle step-over, 6) obstacle walk-around 


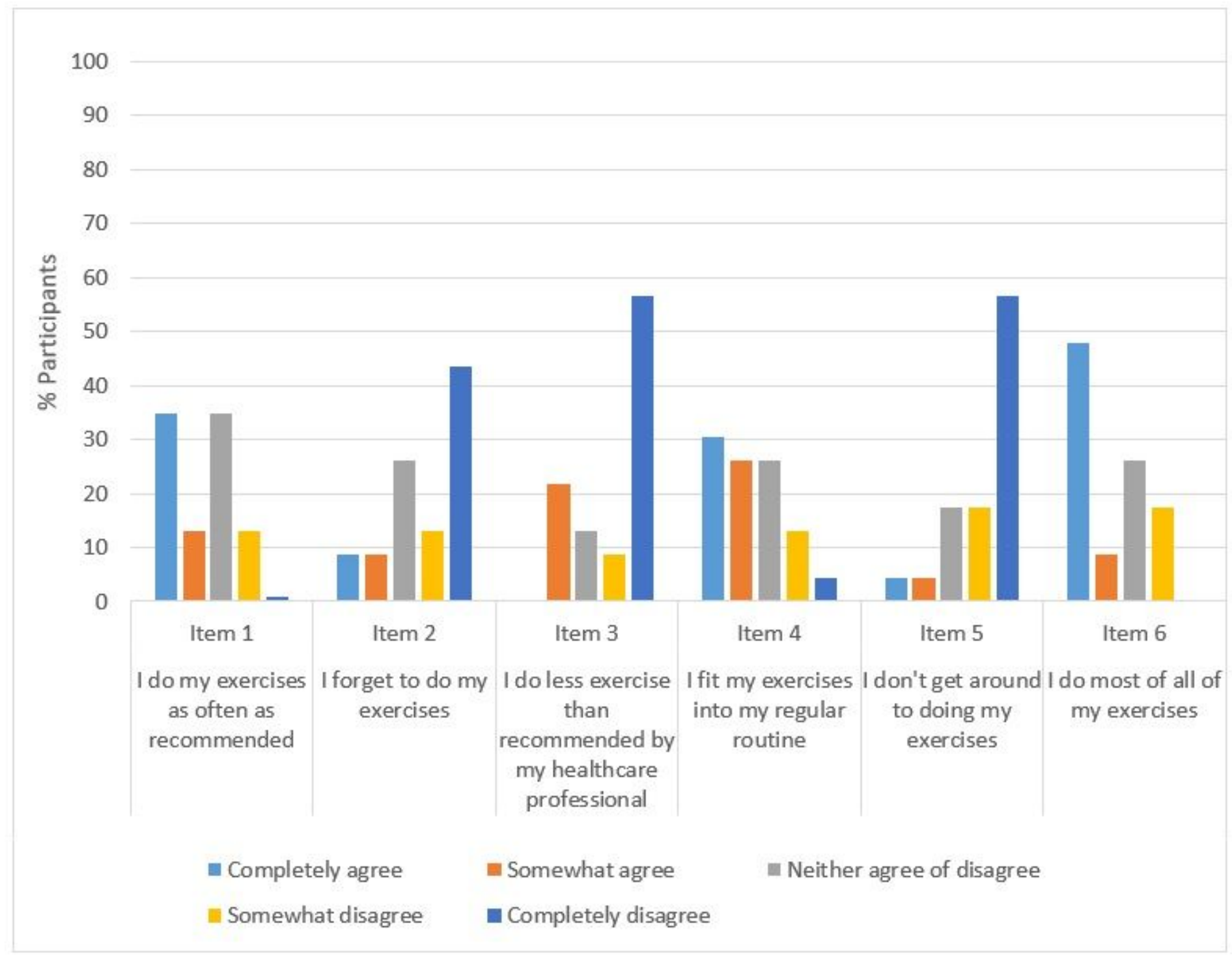

\section{Figure 2}

Exercise Adherence Rating Scale (EARS) item responses at Visit 2 (Week 12). 


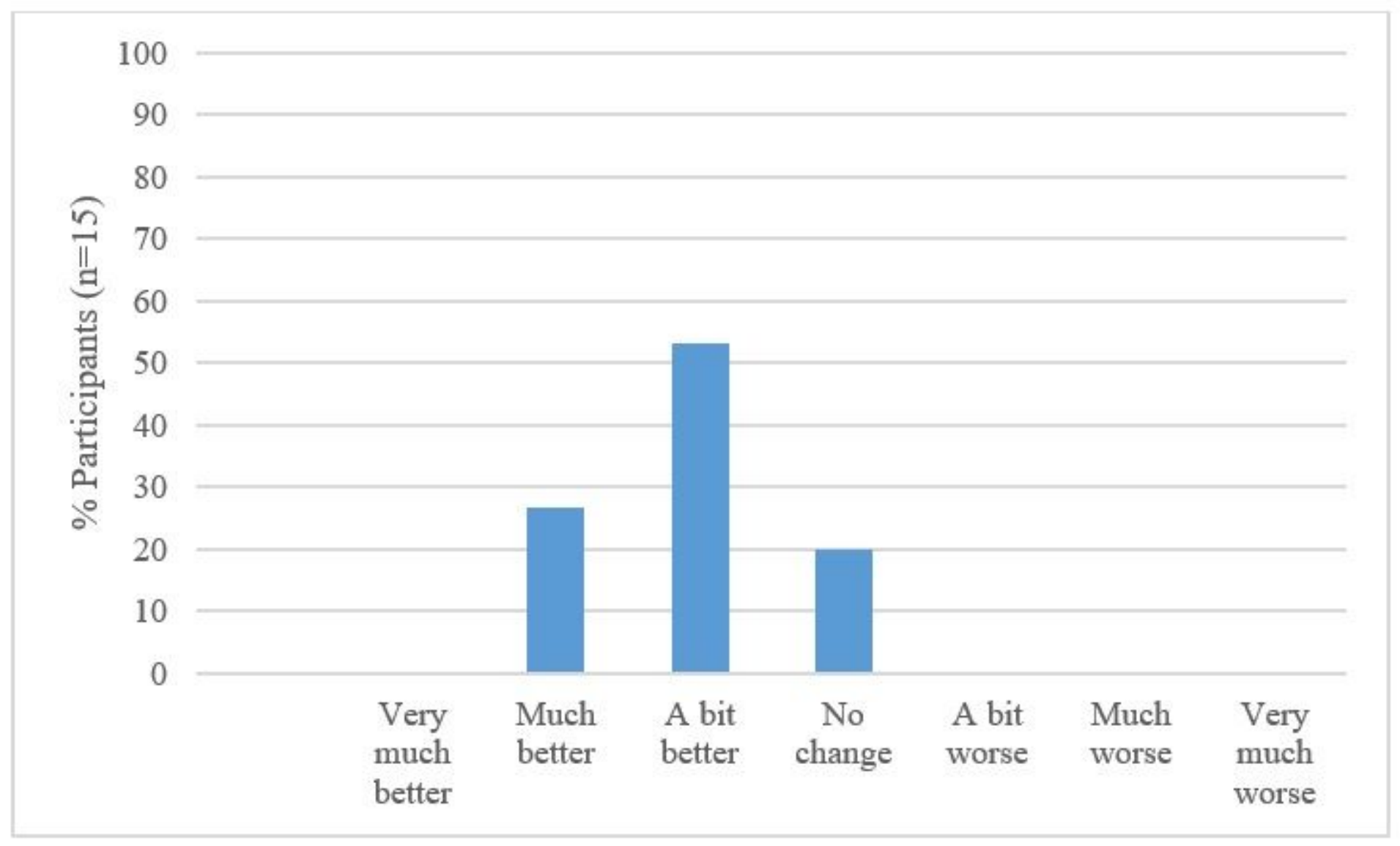

Figure 3

CWA (7-point Likert scale) at 12 weeks. 


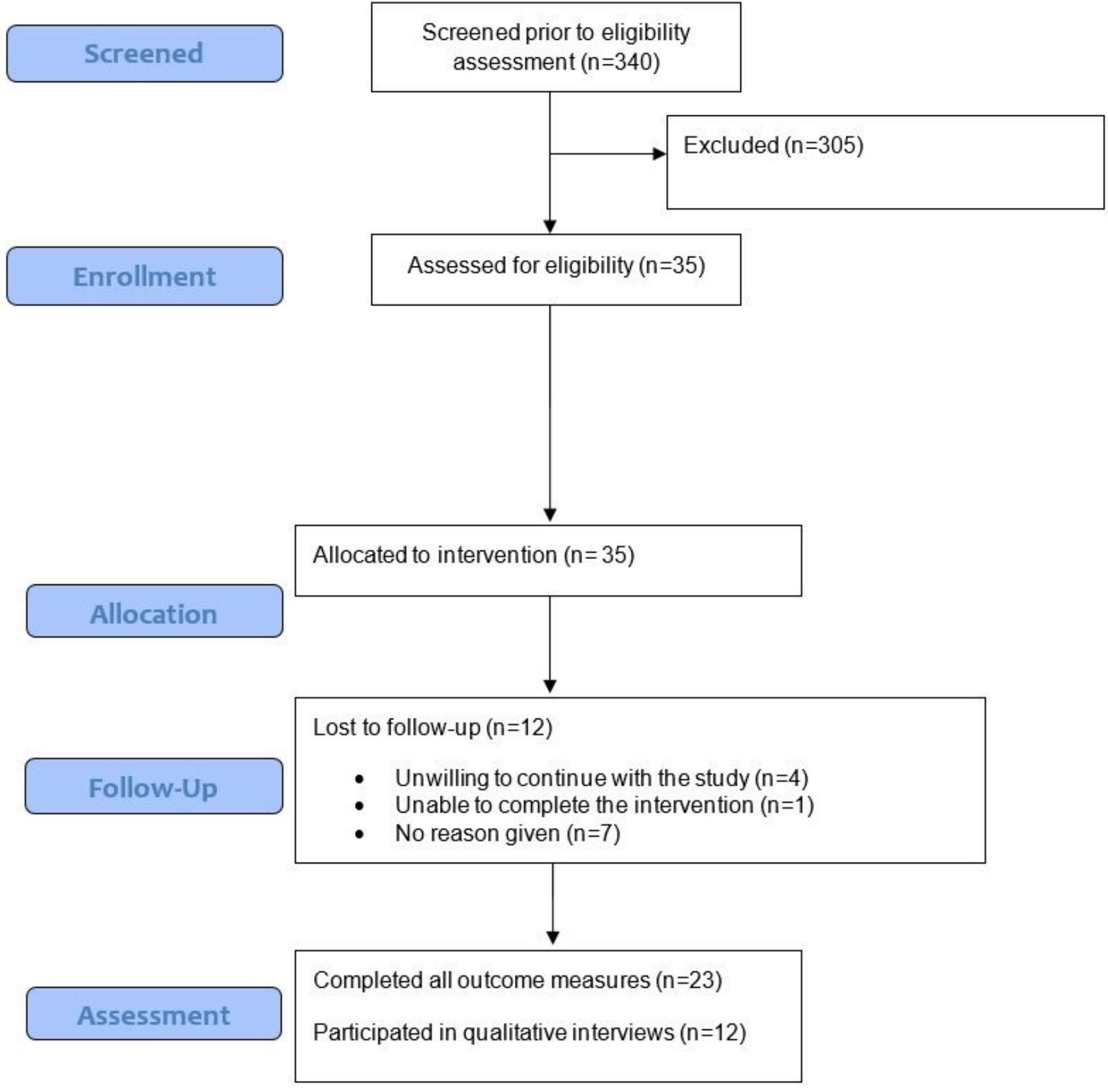

Figure 4

Study flowchart for recruitment.

\section{Supplementary Files}

This is a list of supplementary files associated with this preprint. Click to download.

- Additionalfile1Eventsofspecialinterest.docx

- Additionalfile2Interviewscriptparticipants.docx 
- AdditionalFile3Interviewscripttherapists.docx

- AdditionalFile4fidelity.docx

- Additionalfile5PROMscoresbyCWA.docx

- ChecklistGJH261121.doc 